\title{
Experimental Study on Synergistic Fire Extinguishing between Different Potassium Additives in Water Mist
}

\author{
Zhe Dong, Shao-Kun Wei, and Lin-Shuang Zhao
}

\begin{abstract}
In order to study the synergistic fire extinguishing effect of potassium salt additives in water mist, the fire extinguishing experiments were carried out with the two of seven kinds of potassium salt additives $\left(\mathrm{KNO}_{3}, \mathrm{CH}_{3} \mathrm{COOK}\right.$, $\mathrm{K}_{2} \mathrm{C}_{2} \mathrm{O}_{4}, \mathrm{KCl}, \mathrm{K}_{2} \mathrm{CO}_{3}, \mathrm{~K}_{2} \mathrm{SO}_{4}$ and $\mathrm{KHCO}_{3}$ ) with the same mass fraction. The results show that the fire extinguishing time of $\mathrm{K}_{2} \mathrm{C}_{2} \mathrm{O}_{4}-\mathrm{K}_{2} \mathrm{SO}_{4}, \mathrm{~K}_{2} \mathrm{CO}_{3}-\mathrm{CH}_{3} \mathrm{COOK}, \mathrm{K}_{2} \mathrm{CO}_{3}-\mathrm{KCl}, \mathrm{KNO}_{3}-$ $\mathrm{K}_{2} \mathrm{SO}_{4}, \mathrm{CH}_{3} \mathrm{COOK}-\mathrm{K}_{2} \mathrm{SO}_{4}$ is less than the fire extinguishing time of the single additive, which indicates that the chemical inhibiting effects of the additives are enhanced, and there is a synergistic fire extinguishing effect among the potassium additives combinations which are mentioned above. Finally, the mechanism of the synergistic fire extinguishing effect is conjectured as follows: under the activation of high-temperature steam in the flame zone, a kind of substance after melting or decomposing accelerates the generation rate of fire extinguishing active substances, thereby increasing the extinguishing efficiency.
\end{abstract}

Index Terms-Mechanism, potassium, synergistic effect, water mist.

\section{INTRODUCTION}

Water mist was widely studied and also applied in various situations for its advantage of little pollution, high efficiency, low water consumption, less cost and hazardous effect [1]. However, the ordinary water mist could only be used for physical fire extinguishing and had limitations in special and protected situations. Lott J L et al. showed that there was a synergistic fire extinguishing effect between the gas fire extinguishing agents, $\mathrm{CF}_{3} \mathrm{Br}, \mathrm{CF}_{2} \mathrm{ClBr}$ and $\mathrm{CO}_{2}$ or $\mathrm{N}_{2}$ [2] and more recently, Yang $\mathrm{L}$ et al. discovered that there is a synergistic fire extinguishing effect between the water mist additive, $\mathrm{K}_{2} \mathrm{CO}_{3}, \mathrm{Na}_{2} \mathrm{CO}_{3}$ and $\left(\mathrm{NH}_{4}\right) \mathrm{HCO}_{3}$ [3]. Synergistic of water mist with additives had become a hot research topic in fire safety science. Therefore, the experimental studying the synergistic extinguishing effect of $\mathrm{KNO}_{3}, \mathrm{CH}_{3} \mathrm{COOK}$, $\mathrm{K}_{2} \mathrm{C}_{2} \mathrm{O}_{4}, \mathrm{KCl}, \mathrm{K}_{2} \mathrm{CO}_{3}, \mathrm{~K} 2 \mathrm{SO} 4$ and $\mathrm{KHCO} 3$ was carried out.

\section{EXPERIMENT}

Because the extinguishing time of water mist is easily affected by the environment, such as air pressure, temperature, humidity, etc., in order to measure the effectiveness of the extinguishing efficiency of water mist containing additives and reduce the influence of environmental factors on the experiment, each experiment is

\footnotetext{
Manuscript received June 27, 2018; revised August 23, 2018

The authors are with Beijing Institute of Technology, Beijing, China (e-mail: 452083443@qq.com, 478550071@qq.com, zhaolinshuang@bit.edu.cn).
}

repeated 5 to 10 times. The total mass fraction of potassium salt additive is placed at $5 \%$, and then the above seven kinds of potassium salts were compounded in a 1:1 mass ratio relationship, and the injection pressure is 3.0 MPa. The water mist fire extinguishing experimental device is shown in Fig. 1. The selected oils pan diameter is $20 \mathrm{~cm}$ and the fuel is alcohol. As the atomization effect of water mist is best at the distance of $1 \mathrm{~m}$ from the nozzle and as stipulated in the American Fire Association (NFPA) [4], oil tray is arranged at $1 \mathrm{~m}$ below the nozzle.

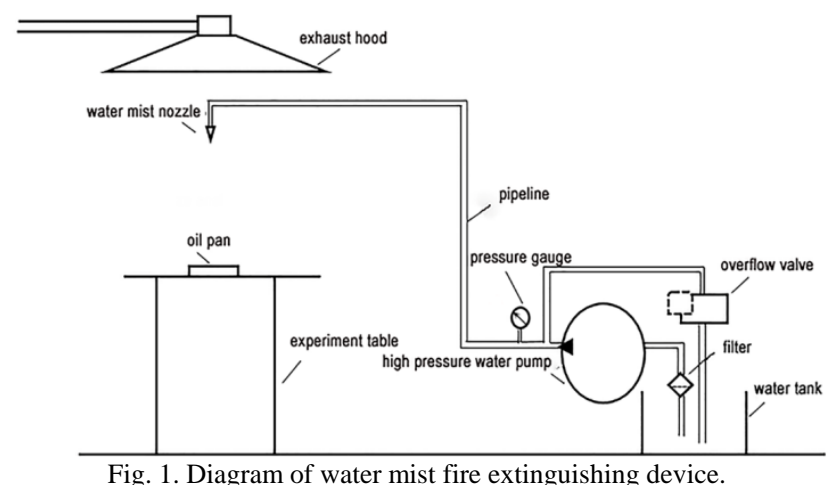

The high-pressure pump is the radial plunger pump, which model is 3DB35 and the material is 314 stainless steel. The pump has the advantages of high rated pressure, compact structure, high efficiency and convenient flow adjustment. The rated power of the plunger pump is $7.5 \mathrm{kw}$, and the normal working pressure is $0 \sim 10 \mathrm{MPa}$.

The type of water mist nozzle is 1/4 FB-SS+FN 16-SS, the entrance joint of which is $1 / 4$ inch, and the flow rate is $1.08 \mathrm{~L} / \mathrm{min}$ when the pressure is $1.0 \mathrm{MPa}$. This type of nozzle is a standard angle nozzle. With a unique internal vortex blade design, the nozzle produces tiny droplets with only a small liquid pressure. The spray shape is 60 degrees solid conical, and the atomization is extremely uniform. It is shown in Fig. 2.

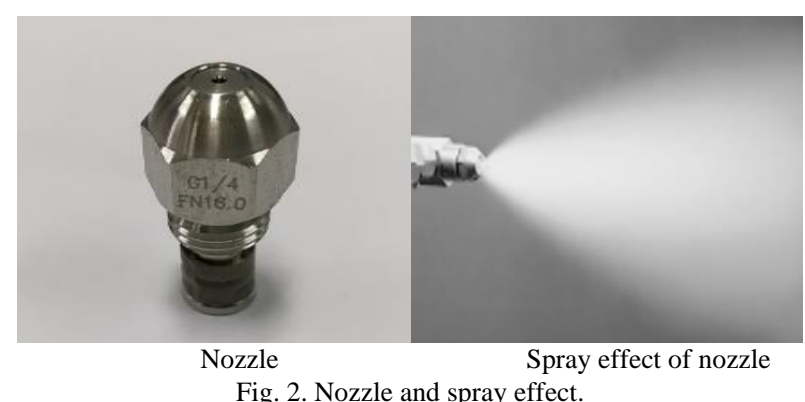

III. RESULTS AND DISCUSSION 


\section{A. Synergistic fire Extinguishing Effect of Different Potassium Additives}

Before researching the synergistic fire extinguishing effect between additives, according to previous studies [5], [6], the extinguishing efficiency of the water mist is not necessarily enhanced with the increase of the additive mass fraction, and water mist extinguishing time will increase with the increase of mass fraction of some additives (such as $\mathrm{K}_{3} \mathrm{PO}_{4}$ ). Therefore, it is necessary to clarify the change rule of the extinguishing efficiency of these seven potassium salt additives when the mass fractions are less than $5 \%$. According to the literature, except $\mathrm{K}_{2} \mathrm{SO}_{4}$, when the mass fractions of the remaining six potassium salt additives are less than 5\%, fire extinguishing efficiency of water mist increases with the increase of mass fraction. But in this case the study of the fire extinguishing efficiency of the water mist with different mass fractions of $\mathrm{K}_{2} \mathrm{SO}_{4}$ is still blank, so it is necessary to conduct the pre-experiment. Water mist extinguishing time and variance results of different mass fractions of $\mathrm{K}_{2} \mathrm{SO}_{4}$ are shown in Table I. Extinguishing efficiency $(\%)=$ (pure water mist extinguishing time - water mist extinguishing time with additives) / pure water mist extinguishing time $\times 100$.

TABLE I: EXTINGUISHING TIME AND VARIANCE OF K2SO4 SOLUTION WITH DIFFERENT CONCENTRATIONS

\begin{tabular}{lllll}
\hline \hline Additive & Mass fraction $/ \%$ & Average extinguishing time /s & Extinguishing time variance & Extinguishing efficiency /\% \\
\hline & 1 & 66.36 & 37.82 & -2.58 \\
$\mathrm{~K}_{2} \mathrm{SO}_{4}$ & 2 & 62.17 & 41.89 & 3.90 \\
& 3 & 58.22 & 62.79 & 9.99 \\
& 5 & 56.86 & 88.72 & 12.10 \\
\hline \hline
\end{tabular}

TABLE II: EXTINGUISHING TIME AND VARIANCE OF WATER Mist WITH DIFFERENT POTASSIUM ADDITIVES

\begin{tabular}{lllll}
\hline \hline Additive & Mass fraction $/ \%$ & Average extinguishing time /s & Extinguishing time variance & Extinguishing efficiency /\% \\
\hline $\mathrm{K}_{2} \mathrm{CO}_{3}$ & 5 & 35.69 & 17.93 & 44.85 \\
$\mathrm{~K}_{2} \mathrm{C}_{2} \mathrm{O}_{4}$ & 5 & 31.95 & 32.76 & 50.62 \\
$\mathrm{~K}_{2} \mathrm{SO}_{4}$ & 5 & 56.86 & 88.72 & 12.13 \\
$\mathrm{KHCO}_{3}$ & 5 & 48.90 & 31.86 & 24.43 \\
$\mathrm{KCl}$ & 5 & 44.61 & 9.81 & 31.05 \\
$\mathrm{CH}_{3} \mathrm{COOK}$ & 5 & 44.00 & 16.65 & 31.99 \\
$\mathrm{KNO}_{3}$ & 5 & 38.48 & 6.11 & 40.52 \\
\hline \hline
\end{tabular}

TABLE III: EXTINGUISHING TIME AND VARIANCE OF WATER Mist WITH COMPOUND POTASSIUM SALT ADDITIVES

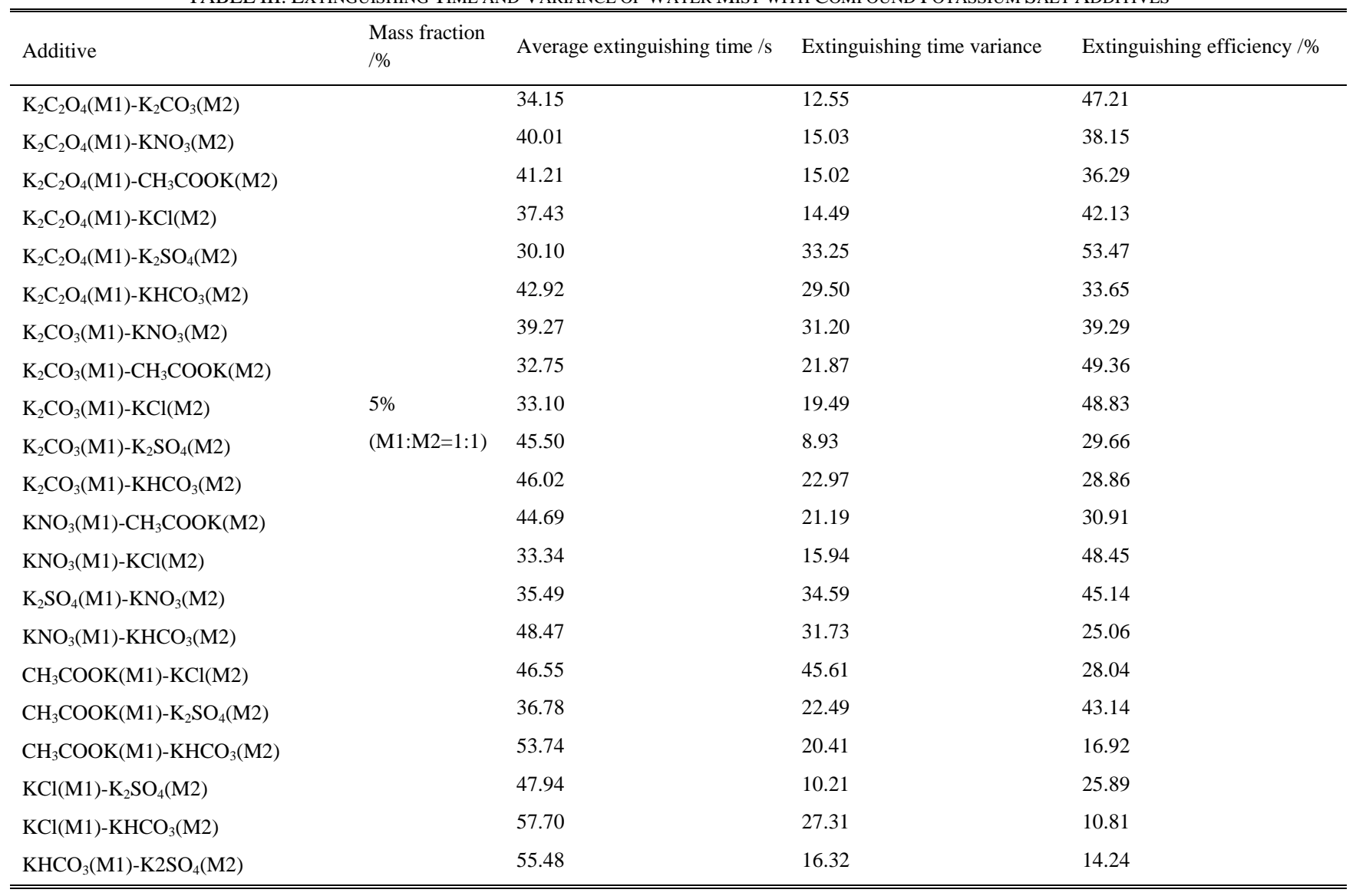


From Table I, we can see that with the increase of $\mathrm{K}_{2} \mathrm{SO}_{4}$ concentration, extinguishing efficiency of water mist is increased, but the variance of extinguishing time is obviously increased, and the stability of fire extinguishing is worse. It is worth noting that the water mist extinguishing efficiency is negative when the mass fraction of $\mathrm{K}_{2} \mathrm{SO}_{4}$ is $1 \%$, which indicates that the fire extinguishing time is slightly greater than fire extinguishing time of pure water mist. This is because the chemical inhibition effect of $\mathrm{K}_{2} \mathrm{SO}_{4}$ in the flame is weaker than the physical fire extinguishing effect of the water mist under this condition.

Through the pre-experiment, it is found that when the mass fraction of the seven kinds of potassium salt additives is less than $5 \%$, the fire extinguishing time decreases with the increase of concentration. Therefore, when the total mass fraction is $5 \%$, it is possible to find out whether there is a synergistic fire extinguishing effect and the separate potassium salt additive can be eliminated. In this case, the fire extinguishing time of water mist with composite potassium salt additives is less than the fire extinguishing time of the single additive (mass fraction of 5\%), so it can be concluded that there is a synergistic effect between the two kinds of potassium salt additives. Table II is the fire extinguishing test result of the alcohol fire model with $5 \%$ of different potassium salt additives. Table III is the experimental result of water mist with seven kinds of potassium salt and the ratio of mass to $1: 1$.

According to Fig. 3 the extinguishing efficiency in order to sort as follows: $\mathrm{K} 2 \mathrm{C} 2 \mathrm{O} 4, \mathrm{~K} 2 \mathrm{CO} 3, \mathrm{KNO} 3, \mathrm{CH} 3 \mathrm{COOK}, \mathrm{KCl}$, $\mathrm{KHCO} 3, \mathrm{~K} 2 \mathrm{SO} 4, \mathrm{H} 2 \mathrm{O}$.

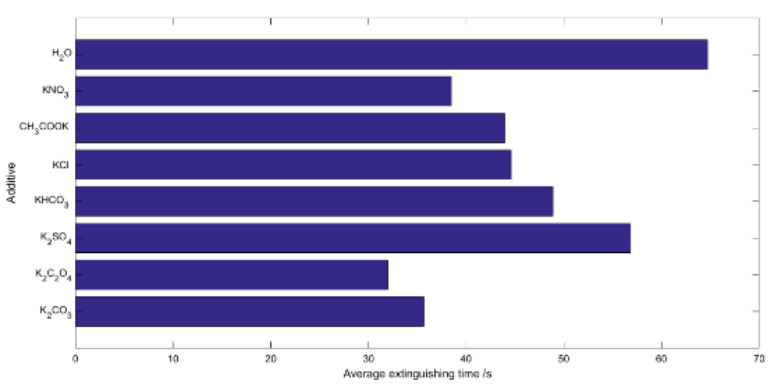

Fig. 3. Fire extinguishing time of water mist with different additives

From Table III, the variance of fire extinguishing time after compounding of $\mathrm{K} 2 \mathrm{C} 2 \mathrm{O} 4$ and $\mathrm{K} 2 \mathrm{SO} 4$ is significantly smaller than that of a single additive, which indicates the extinguishing stability is enhanced, and a good fire extinguishing effect is exhibited. While the fire extinguishing stability of the rest of composite additives is less than two or one of the potassium salt additives. The contrast Table II and Table III show that the fire extinguishing efficiency of $\mathrm{K} 2 \mathrm{C} 2 \mathrm{O} 4-\mathrm{K} 2 \mathrm{SO} 4, \mathrm{~K} 2 \mathrm{CO} 3-\mathrm{CH} 3 \mathrm{COOK}, \mathrm{K} 2 \mathrm{CO} 3-\mathrm{KCl}$, KNO3-K2SO4, CH3COOK-K2SO4 is enhanced, which indicates that chemical inhibiting effects on fire of composite potassium salt additives is enhanced, and there is a synergistic fire extinguishing effect between the composite additives.

\section{B. Discussion and Analysis on Mechanism of Synergistic Fire Extinguishing between Potassium Salt Additives}

Zhang et al. [6] studied that the chemical inhibitory effect is achieved through the release of active chemical extinguishing substances from the water mist with potassium salt additives in the flame. The chemical fire extinguishing process of water mist with the potassium salt additives generally includes the following four steps:

1) The solution is heated up to the boiling point $\left(t_{1}\right)$.

2) Solution evaporation, solute melting or thermal decomposition $\left(\mathrm{t}_{2}\right)$.

3) The molten or decomposed substances can produce fire extinguishing active substances under the activation of high temperature steam $\left(\mathrm{t}_{3}\right)$.

4) The fire extinguishing active substances react with the fire free radicals $\left(t_{4}\right)$.

Chemical fire extinguishing can occur only when the retention time of the water mist droplet in the flame $\left(t_{r}\right)$ is greater than or equal to $t_{1}-t_{2}-t_{3}-t_{4}$, otherwise it cannot be called chemical fire extinguishing in the strict sense. In this experiment, the content of additives is small, and the particle size of water mist is small, which has little effect on time $t_{1}$. According to the experimental results, the fire extinguishing efficiency of $\mathrm{KCl}$ is similar to that of $\mathrm{CH}_{3} \mathrm{COOK}$, while the melting or thermal decomposition temperature of $\mathrm{KCl}$ $\left(758.61^{\circ} \mathrm{C} \sim 779.18^{\circ} \mathrm{C}\right)$ is far higher than the thermal decomposition or melting temperature of $\mathrm{CH}_{3} \mathrm{COOK}$ $\left(313.07^{\circ} \mathrm{C} \sim 606.85^{\circ} \mathrm{C}\right.$ ) which indicates that the time $\mathrm{t}_{2}$ is not the main influence time. Jensen D E studies [7] showed that the time $t_{4}$ for the reaction between the extinguishing active substance and the flame radical is negligibly small. Therefore, it can be inferred that the synergistic fire extinguishing effect between potassium salt mainly occurs within the time $t_{3}$. The synergistic fire extinguishing effect of the potassium salt additives increases the rate of generation of active fire extinguishing substances under the activation of high-temperature steam in the flame zone, thus improving the fire extinguishing efficiency.

\section{CONCLUSIONS}

In this paper, seven kinds of potassium salts, $\mathrm{K}_{2} \mathrm{C}_{2} \mathrm{O}_{4}$, $\mathrm{K}_{2} \mathrm{CO}_{3}, \mathrm{KNO}_{3}, \mathrm{CH}_{3} \mathrm{COOK}, \mathrm{KCl}, \mathrm{KHCO}_{3}$ and $\mathrm{K}_{2} \mathrm{SAO}_{4}$ applied in practical projects are selected as water mist additives. The main conclusions obtained through fire extinguishing experiments are as follows:

1) After the seven kinds of potassium salts were compounded in equal proportions, the fire extinguishing efficiency of $\mathrm{K}_{2} \mathrm{C}_{2} \mathrm{O}_{4}-\mathrm{K}_{2} \mathrm{SO}_{4}$, $\mathrm{K}_{2} \mathrm{CO}_{3}-\mathrm{CH}_{3} \mathrm{COOK}, \quad \mathrm{K}_{2} \mathrm{CO}_{3}-\mathrm{KCl}, \quad \mathrm{KNO}_{3}-\mathrm{K}_{2} \mathrm{SO}_{4}$, $\mathrm{CH}_{3} \mathrm{COOK}-\mathrm{K}_{2} \mathrm{SO}_{4}$ were significantly improved, indicating that the chemical inhibition of the additives is enhanced, and there is a synergistic fire extinguishing effect among the above-mentioned potassium additives combinations.

2) The mechanism of the synergistic fire extinguishing effect between the water mist containing potassium salt additives is given: the potassium salt with synergistic fire extinguishing effect increases the rate of generation of active fire extinguishing substances under the activation of high-temperature steam in the flame zone, thus improving the fire extinguishing efficiency. 


\section{ACKNOWLEDGMENTS}

This paper is supported by the National Key R\&D Program of China (2016YFC0801500).

\section{REFERENCES}

[1] J. R. Mawhinney and G. G. B. Iii, Water Mist Fire Suppression Systems, Springer New York, 2016, pp. 1587-1645.

[2] J. L. Lott et al., "Synergism between chemical and physical fire-suppressant agents, Book Synergism between chemical and physical fire-suppressant agents, Series Synergism between chemical and physical fire-suppressant agents 32,"1996, pp. 260-271.

[3] L. Yang and J. Zhao, "Fire extinct experiments with water mist by adding additives," J THERM SCI, vol. 20, no. 6, pp. 563-569, pp. 2011.

[4] M. D. Rumminger et al., "Numerical study of the inhibition of premixed and diffusion flames by iron pentacarbonyl," Combustion \& Flame, vol. 128, no. 1-2, pp. 145-164, 1999.
[5] Liu Zhong-Lin, "Study on the fire extinguishing efficiency of new water-based additives," Zhengzhou University, Zhengzhou, China, 2015.

[6] Zhang Tian-Wei, "Fire-extinguishing performance and mechanism study on water mist with potassium additives," Beijing Institute of Technology, Beijing, China, 2017.

[7] D. E. Jensen and G. A. Jones, "Reaction rate coefficients for flame calculations," Combustion \& Flame, vol. 32, pp. 1-34, 1978.

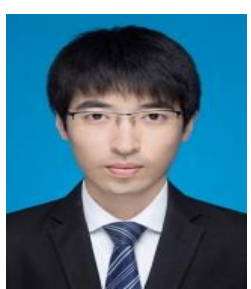

Zhe Dong received the bachelor's degree with safety engineering, Hebei University of Technology, Tianjin, China, in 2016. He is currently pursuing the master's degree with the safety science and engineering, Beijing Institute of Technology, Beijing, China, since 2016. His research interests include fire monitoring and fire extinguishing agent. 